\title{
A RIVALIDADE ENTRE ESTADOS UNIDOS E UNIÃO SOVIÉTICA E A PROMOÇÃO DO DESENVOLVIMENTO NA PERIFERIA GLOBAL'
}

Pedro Rocha Fleury Curado²

\section{Resumo}

O presente artigo objetiva analisar o papel da "teoria da modernização" e da "teoria do desenvolvimento não-capitalista" como base para a elaboração dos programas de ajuda internacional de Estados Unidos e União Soviética no âmbito da Guerra Fria. Ambas as teorias foram elaboradas em resposta à crescente rivalidade sistêmica entre as duas superpotências e em sincronia com os objetivos de projeção geopolítica de cada uma delas. Analisando cada caso, o texto argumenta que, a despeito da rivalidade, existiam semelhanças substanciais na forma como cada corrente teórica concebia as políticas necessárias para o desenvolvimento econômico nos países da periferia global.

Palavras-chave: Modernização, Desenvolvimento não-capitalista, Guerra Fria, Cooperação Internacional, Terceiro Mundo.

\section{Classificação JEL: F51}

O presente trabalho abordará o tema da cooperação para o desenvolvimento no seu contexto histórico de origem, isto é, a Guerra Fria. O objetivo será localizar e identificar a relação existente entre as concepções teóricas de desenvolvimento para a periferia apresentadas por Estados Unidos e União Soviética e a política de potência de ambos os Estados. Para tanto,

Este trabalho é o desenvolvimento de um tópico abordado na Tese de Doutorado "A Guerra Fria e a cooperação ao desenvolvimento com os países não-alinhados: um estudo de caso sobre o Egito Nasserista (1955- 1967)", apresentada no Programa de Pós-Graduação em Economia Política Internacional da universidade Federal do Rio de Janeiro -PEPI/UFRJ.

Artigo original preparado para o VIII Colóquio Brasileiro em Economia Política dos Sistemas-Mundo.

2 Doutor em Economia Política Internacional pela UFRJ. E-mail: pedro.917@gmail.com 
será feita uma análise comparativa sobre a forma como a promoção do desenvolvimento no terceiro mundo foi concebida pelos estrategistas e Think Tanks de ambas as superpotências. Buscaremos, em cada caso, sublinhar os princípios basilares que definem a lógica interna pela qual o instrumento da cooperação se aplica, assim como sua potencial funcionalidade geoestratégica no contexto da rivalidade bipolar sistêmica. Argumentaremos que embora cada programa fosse concebido de maneira a explicitar a eficiência do modelo de Estado de uma das superpotências em detrimento da outra, ambos terminavam por refletir na prática o apoio para a implantação de políticas econômicas substancialmente similares.

\section{O CONCEITO DE "DESENVOLVIMENTO" E A POLÍTICA EXTERNA DAS SUPERPOTÊNCIAS NO PÓS-SEGUNDA GRANDE GUERRA}

O desenvolvimento é um conceito em disputa dentro dos estudos da área de ciências humanas. Sem uma definição consensual, o termo é usado freqüentemente em discursos políticos e estudos acadêmicos, sendo o progresso, a melhoria, o avanço ou a modernização alguns dos sentidos comumente derivados. Por ser genérico, é não raramente subdividido no plano discursivo e programático em áreas como "desenvolvimento econômico", "desenvolvimento social", "desenvolvimento tecnológico" etc. Em termos conceituais, quando defini-se "desenvolvimento", sugere-se igualmente a idéia dicotômica entre o que já é "desenvolvido" e o "não-desenvolvido", ou o estado onde o desenvolvimento estaria ausente.

A definição do significado da palavra "desenvolvimento" tornou-se basilar para a construção de teorias que ainda hoje orientam as políticas de "ajuda externa" ou "cooperação para o desenvolvimento" . Criadas no contexto da Guerra Fria e no processo de descolonização, elas perduram atualmente tanto em políticas individuais de determinados países como em programas organizados no âmbito de agências multilaterais, como a ONU e o Banco Mundial.

\footnotetext{
Os termos "ajuda" e "cooperação" serão tratados como sinônimos neste texto. Lembramos, entretanto, que na literatura os termos nem sempre são vistos com o mesmo significado. No âmbito do discurso político dos países em desenvolvimento, por exemplo, existem governos que preferem utilizar o termo "cooperação" para enfatizar o caráter horizontal e recíproco da política posta em prática.
} 
No pós-Segunda Guerra, o conceito de “desenvolvimento" e, em particular, a "promoção ao desenvolvimento" na periferia global esteve diretamente associado à política externa de Estados Unidos e União Soviética. Sua aplicação, seja por um ou pelo outro, estava orientada por teorias evolucionistas e normativas que, sincronizadas com o interesse de cada potência em projetar-se sobre a periferia global, serviam aos objetivos de ordem geopolítica. Para compreendermos o contexto histórico onde o termo e a prática são forjados, cumpre a realização de uma breve reconstituição do período no qual tal política adquiriu relevância.

A conferência de Yalta, em 1945, inaugura a nova Ordem mundial bipolar, onde Estados Unidos e União Soviética são as superpotências globais, com zonas de influência extra-territoriais demarcadas e reconhecidas. Novas instituições são criadas para a regulação das relações entre os antigos Estados beligerantes, dentre as quais destaca-se a Organização das Nações Unidas -ONU- (1945). Antes desta, a reunião de Bretton Woods, em 1944, havia redefinido o dólar como moeda de referência para o comércio internacional (através da sua paridade com o ouro) e estabelecido a criação das seguintes instituições multilaterais: a) o Acordo Geral de Tarifas e Comércio -GATT- (1947), com a função de harmonizar as políticas aduaneiras dos Estados signatários e impulsionar o comércio internacional do pós-guerra; b) o Fundo Monetário Internacional -FMI- (1946), com o objetivo anunciado de reconstruir o sistema monetário internacional; e c) o Banco Mundial -BM- (1946), voltado à assistência ao desenvolvimento em países de "renda média". De maneira geral, os objetivos de tais iniciativas estavam voltados à criação de instituições que funcionassem como um sistema de pagamentos para apoiar a economia expansiva e, assim, viabilizar a reconstrução do mundo europeu do pós-guerra.

A implementação dos termos de Bretton Woods foi também influenciada pelo ambiente de Guerra Fria, já que contou com o apoio unilateral dos Estados Unidos aos seus aliados estratégicos por intermédio tanto de programas de reconstrução das economias nacionais européias como de uma política unilateral de abertura. Tal medida fazia da expansão do mercado interno estadunidense e da valorização de sua taxa de câmbio face aos demais uma maneira de favorecer as exportações agrícolas destes para os Estados Unidos. Este mecanismo levará à produção de uma liquidez diferenciada 
na economia mundial: para aquelas economias que estivessem inscritas como objetos dos investimentos da parte dos Estados Unidos, o programa de desenvolvimento econômico interno será impulsionado pela liquidez de divisas. Aos demais, escassez de divisas. Os países que gozassem de liquidez de divisas iriam encontrar grande margem para o desenvolvimento econômico por conta da expansão da economia mundial que ocorria no mesmo período.

Valendo-se de tais mecanismos diplomáticos e econômicos, os Estados Unidos utilizaram sua estabilidade interna para definir uma estratégia de projeção externa na qual fosse ele o vetor da reconstrução da Europa e do Japão. Entretanto, um outro processo histórico paralelo atingia seu momento culminante no pós-Segunda Guerra. Quando o Plano Marshall (1947) fora lançado pelos Estados Unidos para contemplar especificamente os mencionados objetivos de reconstrução das economias ocidentais devastadas pela guerra, novos Estados surgidos de movimentos independentistas na África e Ásia, herdeiros de estruturas de produção coloniais, passaram a também pressionar por medidas favoráveis na forma de incentivos por parte dos centros do comércio global. Com isso, pretendiam fustigar uma melhor inserção na economia internacional e, conseqüentemente, uma postura mais atenciosa às suas demandas por desenvolvimento econômico por parte dos países ricos.

Organizações internacionais, como o Banco Mundial e o FMI, encarregaram-se de criar programas particulares de ajuda aos países da periferia capitalista que cumprissem com certas exigências. O desenvolvimento econômico, neste quadro, era algo que deveria ser induzido pelas políticas de Estado, e este processo de indução era reconhecido de maneira consensual em sua época, isto é, tratava-se de um preceito comum partilhado tanto por técnicos e acadêmicos como pelas instituições multilaterais criadas por Washington como o Banco Mundial. A meta anunciada era viabilizar o "take off', isto é, dar a partida para um processo de desenvolvimento econômico acelerado, associado à criação de uma estrutura produtiva industrial e à transformação das técnicas de produção agrícolas. Como resultado esperado, os Estados periféricos adentrariam ao nível de vida e consumo das sociedades urbanas industriais ocidentais no médio prazo, uma vez que o processo fosse também acompanhado pela "modernização do corpo sócio 
-político". Por "modernização", neste caso, entendia-se a ocidentalização das instituições e da lógica administrativa da máquina estatal, dado que na maior parte do globo, e em particular nos novos Estados da África e Ásia, coexistiam sistemas de organização social nativos e estruturas produtivas do capitalismo dependente herdadas do período colonial, estruturadas sobre a exportação de matérias-primas para o mercado europeu. A política de "modernização", sempre concebida de cima para baixo, viria fortalecer o processo de criação de um Estado e uma sociedade ao modelo europeu fora da Europa, superando as resistências "tradicionais" locais.

Cumpre aqui a interrupção dessa narrativa histórica para uma breve contextualização do uso político da palavra "desenvolvimento" no contexto da Guerra Fria. Este é um termo particularmente significativo, haja visto sua capacidade de redefinir os sistemas de compreensão que irão conferir sentido às ações políticas subseqüentes. Nos anos 1950, o desenvolvimento econômico passa a ser uma prioridade anunciada pela maioria dos governos "emergentes" da periferia mundial. A idéia corrente entendia que os desequilíbrios e o "atraso do subdesenvolvimento" não encontram formas de evolução no mercado, mas sim em instituições, nas formas de intervenção estatal, políticas protecionistas, etc. De certa maneira, havia consenso sobre a importância da intervenção estatal como vetor de desenvolvimento econômico. Abandonar esta prática seria condenar a economia a uma espécie de "reprodução do atraso e do subdesenvolvimento". ${ }^{4}$

Essa noção geral sobre o conceito de "desenvolvimento" amplamente difundida será, no âmbito da Guerra Fria, re-apropriada pela geopolítica do conflito bipolar a medida em que as superpotências irão rivalizar, também, na exportação do "modelo de desenvolvimento" mais eficiente para se atingir a "modernidade". Por esta razão, o impacto ocasionado pelo movimento de descolonização e a conseqüente criação quase sincronizada de uma gama de novos Estados na África e na Ásia incorporou à sua agenda o desenvolvimento e a cooperação como objetivos ${ }^{5}$. O processo de descolonização foi

Sobre este aspecto, ver BASTOS,C. \& BRITO,G. (20 I 0). Introdução. In AGARWALA, A.N. \& SINGH, S.P. (org.) A economia do subdesenvolvimento. Ver também ROS, J. (2005) The pioneers of developmente economics. In: JOMO, K.S. \& REINERT, E.S. The origins of development economics.

$\mathrm{Na}$ Carta da Conferência de Bandung (1955), por exemplo, existem diversos itens dedicados a conceituar e detalhar a "cooperação para o desenvolvimento" como um dos objetivos a serem promovidos pelos países participantes. A Conferência de Bandung é visto por diversos autores como um marco de criação do movimento "terceiro-mundista". Ver CONTE, A. (1965) Bandung, tournant de l'histoire. 
decisivo tanto para a reformulação da política externa de Estados Unidos e União Soviética como, de maneira mais profunda, para a própria forma como os estrategistas destes dois países interpretam a geopolítica mundial. A emergência dos novos Estados complexificava a divisão das zonas de influência anteriormente aceitas na Conferência de Yalta.

Importante lembrar que a dicotomia entre capitalismo e comunismo, por sua vez, também repercutia sob o plano político doméstico das novas Nações, já que estas importavam o conflito bipolar para dentro do conflito entre forças domésticas, expresso na relação entre partidos, organizações, movimentos políticos e sociais. O mesmo vale dizer para os ditos projetos de desenvolvimento ou as experiências "nacionais-desenvolvimentistas" nativas de parte dos novos países pós-coloniais, que dependiam de cooperação internacional definida a partir de termos circunstanciados pelo contexto da Guerra Fria.

O novo mundo pós-colonial, portanto, inscrevia-se na hierarquia do sistema internacional através de sua relação com a Guerra Fria. Como conseqüência da formação de novos Estados na África e Ásia, nota-se a diminuição não linear da presença imperial das antigas potências européias do pré-Segunda Guerra, em particular França e Inglaterra, e, com isso, um certo vácuo de poder de gerência regional que será preenchido pela rivalidade bipolar. Contribuirá para isso, é preciso lembrar, a ausência de estruturas estatais sócio-políticas consolidadas na maior parte dos novos países, somado ao caráter multi-étnico próprio a diversos territórios nacionais herdados de demarcações coloniais obedientes à uma lógica de dominação exterior, o que necessariamente acarretava na vulnerabilidade estrutural dos meios domésticos de se exercer o poder e produzir a obediência.

Será, portanto, num ambiente internacional caracterizado pela formação de uma nova Ordem bipolar e a emergência de um amplo movimento de descolonização na periferia global de territórios antes controlados pela antigas potências européias que ocorrerá a aplicação massiva da cooperação ao desenvolvimento como instrumento de política externa.

Como já dito, políticas estatais e instituições internacionais foram criadas com o objetivo explícito de promover o desenvolvimento tanto na Europa como em países "atrasados". Vejamos portanto alguns eventos definidores dessa nova conjuntura do pós-Segunda Guerra. Além do já citado 
Plano Marshall, de 1947, dedicado a prover ajuda econômica à Europa e possibilitar o escoamento do alargado potencial produtivo estadunidense, que por sua vez buscava mercados para ser reconvertido após o fim do conflito, a União Soviética buscava consolidar suas posições em territórios além-fronteiras. No mesmo ano do Plano Marshall, a Polônia, sob patrocínio soviético mudava seu regime para uma "democracia popular", sendo tal modelo seguido no ano seguinte pela Checoslováquia e Romênia e, em 1949, pela Hungria. Em 1948, após um período de deterioração das relações entre União Soviética e os três países ocidentais que ocupavam a parte oeste da Alemanha (isto é, França, Grã-Bretanha e Estados Unidos), Moscou decide interditar o acesso por rota terrestre entre a parte ocidental e Berlim. A China, por sua vez, tornava-se comunista em 1949.

Em comparação à política estadunidense, entretanto, o expansionismo soviético no imediato pós-Segunda Guerra foi restrito. A União Soviética de Joseph Stalin, que por sua vez havia se negado a participar do sistema de Bretton Woods, mantinha a autarquia econômica que caracterizava seu governo através dos planos qüinqüenais, e ao mesmo tempo buscava expandir seu poder político e militar sobre os países da Europa do leste. Nos anos subseqüentes à Segunda Guerra, preocupava-se prioritariamente em reerguer a própria indústria, as Forças Armadas e a auto-suficiência sem se submeter à nova ordem delineada pelos Estados Unidos ao mundo capitalista. Será a morte de Stálin, aliado à força do movimento pela descolonização que pressionarão os soviéticos a redefinirem sua política externa principalmente para a África e Ásia, adotando para tanto suas próprias políticas de cooperação para o desenvolvimento.

Por fim, resta destacar como as políticas de cooperação com o terceiro mundo se aliavam às políticas securitárias de ambos os blocos. A nova conjuntura histórica, repleta de transformações no sistema de alianças global, implicava na tomada de novas medidas de defesa. Em 1949, os Estados Unidos, junto aos países europeus, criavam a Organização do Tratado do Atlântico Norte -OTAN-. ${ }^{6}$ Entre 1950 e 1953, ocorre a Guerra da Coréia, que representou o primeiro confronto bélico da Guerra Fria dentro de um

Os países membro fundadores da OTAN eram Estados Unidos, Portugal, Bélgica, Canadá, Dinamarca, França, Islândia, Itália, Luxemburgo, Países Baixos, Reino Unidos e Noruega. 
país da periferia global e reforçou o objetivo norte-americano de fazer pesar sua influência sobre esta. Como conseqüência, as ações americanas nessa região do mundo passaram a ser mais incisivas. A administração Eisenhower (1953-1960) buscava contrapor a projeção comunista nas regiões que considerava mais vulneráveis, isto é, o entorno geográfico próximo às fronteiras soviéticas e chinesas. ${ }^{7}$ A conhecida estratégia de containment, isto é, a política de contenção da expansão soviética através do cercamento das margens terrestres de seu território, resultou num primeiro momento no apoio militar estadunidense aos vietnamitas do sul, após a derrota francesa na batalha de Dien Bien Phu. Em 1953, o governo Eisenhower colaborou com o golpe de Estado no Irã orquestrado após a nacionalização das empresas petrolíferas. Um ano após, dessa vez agindo sobre uma zona distante das fronteiras russas mas já dentro da lógica de assegurar aliados no jogo da Guerra Fria, agentes do Estado americano conspiram a favor do golpe de Estado do presidente guatemalteco eleito Jacob Arbenz. ${ }^{8}$ Em 1955, será a vez dos soviéticos criarem seu sistema de defesa com o Pacto de Varsóvia. ${ }^{9}$ Será na evolução destes acontecimentos, onde o "Sul" do mundo começava a emergir como espaço de importância geopolítica dentro da gradual complexificação do conflito Leste-Oeste, que o conceito "desenvolvimento" se consolidará em um instrumento de primeira ordem para a política externa, em sincronia com a política de segurança. ${ }^{10}$

O evento que marca a incorporação definitiva do "desenvolvimento" na agenda política internacional americana e, conseqüentemente, de outras nações, será o discurso pronunciado por Harry Truman em 20 de janeiro de 1949, quanto este anuncia a criação dos quatro pontos que norteariam a política externa estadunidense nos anos da Guerra Fria. Enquanto os três primeiros pontos se distinguiam entre o apoio à $\mathrm{ONU}$, o apoio à reconstrução européia através do Plano Marshall e a criação da OTAN, será o conteúdo do quarto ponto que irá nos interessar mais diretamente: trata-se da ajuda econômica e técnica aos países "subdesenvolvidos", "pacíficos" e "livres", que estivessem dispostos a empreender esforços de cooperação

KENNEDY, P. (1989) Ascensão e queda das grandes potências: 359.

8 MONIZ BANDEIRA, L. (2005) A formação do império americano: 182.

9 Participavam do Pacto de Varsóvia Alemanha Oriental, Bulgária, Hungria, Polônia, Checoslováquia, Romênia e Albânia.

10 RIST, G. (2013) Le développement, Histoire d'une croyance occidentale: I 32. 
para alcançar o "progresso e o desenvolvimento". Segundo as palavras de Truman, o Ponto IV foi definido da seguinte forma:

Fourth, we must embark on a bold new program for making the benefits of our scientific advances and industrial progress available for the improvement and growth of underdeveloped areas. More than half the people of the world are living in conditions approaching misery. Their food is inadequate. They are victims of disease. Their economic life is primitive and stagnant. Their poverty is a handicap and a threat both to them and to more prosperous areas. For the first time in history, humanity possesses the knowledge and the skill to relieve the suffering of these people. The United States is pre-eminent among nations in the development of industrial and scientific techniques. The material resources which we can afford to use for the assistance of other peoples are limited. But our imponderable resources in technical knowledge are constantly growing and are inexhaustible. I believe that we should make available to peace-loving peoples the benefits of our store of technical knowledge in order to help them realize their aspirations for a better life. And, in cooperation with other nations, we should foster capital investment in areas needing development. Our aim should be to help the free peoples of the world, through their own efforts, to produce more food, more clothing, more materials for housing, and more mechanical power to lighten their burdens. We invite other countries to pool their technological resources in this undertaking. Their contributions will be warmly welcomed. This should be a cooperative enterprise in which all nations work together through the United Nations and its specialized agencies wherever practicable. It must be a worldwide effort for the achievement of peace, plenty, and freedom. With the cooperation of business, private capital, agriculture, and labor in this country, this program can greatly increase the industrial activity in other nations and can raise substantially their standards of living. Such new economic developments must be devised and controlled to benefit the peoples of the areas in which they are established. Guarantees to the investor must be balanced by guarantees in the interest of the people whose resources and whose labor go into these developments. The old imperialism - exploitation for foreign profit - has no place in our plans. What we envisage is a program of 
development based on the concepts of democratic fair-dealing. All countries, including our own, will greatly benefit from a constructive program for the better use of the world's human and natural resources. Experience shows that our commerce with other countries expands as they progress industrially and economically. Greater production is the key to prosperity and peace. And the key to greater production is a wider and more vigorous application of modern scientific and technical knowledge. Only by helping the least fortunate of its members to help themselves can the human family achieve the decent, satisfying life that is the right of all people. Democracy alone can supply the vitalizing force to stir the peoples of the world into triumphant action, not only against their human oppressors, but also against their ancient enemies — hunger, misery, and despair. ${ }^{11}$

Diversos autores sublinham o Point IV como evento desencadeador de uma transformação estrutural nas relações entre as potências da Nova Ordem e os países do terceiro mundo. ${ }^{12} \mathrm{O}$ modo de se referir ao "desenvolvimento" e a disposição dos Estados Unidos em exercer um papel importante na promoção do mesmo demarcava uma nova fase, em vias de se configurar, da relação dinâmica entre os países "ricos" e "pobres". Isso significava dizer que a anterior oposição entre colonizadores e colonizados seria substituída por uma nova relação Norte-Sul. A nova dicotomia "desenvolvidos /subdesenvolvidos", por conseqüência, definiria uma relação diferente, que estaria em conformidade à Carta das Nações Unidas ${ }^{13}$ e a progressiva "mundialização" do sistema interestatal. A antiga relação hierárquica de colônias submissas à metrópole daria lugar a um mundo no qual todos os Estados seriam formalmente iguais no direito mesmo que eles não o fossem de fato, algo verificado na hierarquia estabelecida entre os Estados pelas capacidades bélicas e as potencialidades econômicas que, em última instância, eram refletidas na própria capacidade destes em influir sobre as instituições multilaterais recém-criadas. Em segundo lugar, o par "desenvolvimento / subdesenvolvimento" manteria a existência de uma separação dicotômica

"Point Four Speech. Em: http://www.bartleby.com/I24/pres53.html. Acessado dia I0/I0/2013.

12 Ver, por exemplo, RIST, G. (20 I3) Le développement, Histoire d'une croyance occidentale: I3 I- 146.

13 Datada de 1945, a Carta das Nações Unidas dedicada o capítulo IX a elaborar princípios para a "cooperação econômica e social internacional" 
entre diversas partes do mundo e construiria uma maneira de justificar e legitimar uma intervenção nas zonas subdesenvolvidas. ${ }^{14}$

$\mathrm{O}$ autor Gilbert Rist ressalta o efeito de propaganda das políticas de cooperação ao desenvolvimento para a imagem dos Estados Unidos, já que será a partir do anúncio do Point $I V$ que este se apresentará como um ator interessado no bem comum planetário, propondo o "desenvolvimento" como um conjunto de medidas técnicas (como conhecimento científico, crescimento da produtividade, intensificação das trocas internacionais) então apresentadas como neutras e situadas fora do debate político. Mais do que isso, ao definir o "subdesenvolvimento" como um estado de ausência, antes que um fruto de circunstâncias históricas, e ao apresentar os "subdesenvolvidos" como pobres sem observar as razões da pobreza, o Point IV fazia do crescimento econômico e da ajuda externa, fornecida pelo Estado "desenvolvido" e altruísta, a única via possível para o "desenvolvimento". ${ }^{15}$

Voltando ao ambiente político internacional e à promoção do desenvolvimento no pós-Segunda Grande Guerra, é preciso considerar ainda o papel exercido pela ONU como instância viabilizadora dos novos mecanismos para a cooperação. Em 1949, a Assembléia Geral aprovou a criação do Programa Ampliado de Assistência Técnica (PAAT), alimentado por contribuições voluntárias dos Estados-membro. Os fundos seriam destinados principalmente para o financiamento do envio de técnicos, para fornecer bolsas aos profissionais do Terceiro Mundo e para a formação de quadros da administração pública nativa. As demandas por assistência deveriam ser depositadas pelos governos, e um escritório de assistência técnica, composto por diretores de agências especializadas, organizaria os programas e supervisionaria a imparcialidade e a alocação de fundos disponíveis. A partir de então, um comitê permanente de assistência técnica, composto por membros do Conselho econômico e social, trataria de examinar os projetos apresentados e asseguraria que estes não constituíssem uma forma de ingerência. Este mecanismo permitiria dividir as responsabilidades entre os fornecedores e assim internacionalizar a concessão de ajuda entre os países pós-coloniais. Toda a assistência técnica fornecida deveria ser complementada por um regime de transferência de capitais.

${ }_{14}$ RIST, G. (20।3) Le développement, Histoire d'une croyance occidentale: I37- I38.

15 Idem: |32-|4|. 
Entretanto, como mostra o trabalho de Paterson, ${ }^{16}$ embora tal programa tenha tido desde o início grande repercussão, os investimentos privados foram parcamente estimulados e sua representatividade, se comparados com aqueles direcionados para a Europa ocidental, era bastante reduzida. ${ }^{17}$ Como tal aspecto recebeu pouco incentivo, a área de concentração do Point IV acabou por ser a assistência técnica. Assim, técnicos viajaram a diversos países e implementaram programas locais com resultados de pouca expressão. ${ }^{18}$ As críticas começaram a surgir justamente a partir dos líderes de governos nacionalistas. Já em 1953, um delegado indiano disse na ONU que a assistência técnica servia para extrair matérias-primas de países pobres e direcioná-las à países industrializados. A Síria, por sua vez, recusou no mesmo ano a assistência estadunidense e o presidente Gamal Nasser, no Egito, classificou o Point IV como uma nova forma de penetração colonial. ${ }^{19} \mathrm{~A}$ forma como os programas eram implementados era o principal alvo das críticas, já que respondiam exclusivamente a demandas externas ao país receptor.

É preciso ainda ressaltar o papel dos soviéticos ao longo do período em questão. Até 1953, enquanto Joseph Stalin ainda era vivo, a União Soviética usou seu poder de veto para bloquear todas as tentativas estadunidenses em criar, através da ONU, instituições dotadas da funções para "promover o desenvolvimento" nos países periféricos. Porém, com a ofensiva econômica soviética no Terceiro Mundo a partir de Khrushchev, a União Soviética irá redirecionar sua política externa e desenvolver, em termos teóricos e práticos, seu próprio programa concorrencial de ajuda ao desenvolvimento.

Essa progressiva participação soviética em projetos de desenvolvimento domésticos próprios de países periféricos ${ }^{20}$ exerceu nova pressão sobre os programas de ajuda externa dos Estados Unidos, elevando o interesse estadunidense em fazer avançar políticas de maior amplitude. A conseqüência

\footnotetext{
PATERSON, T. (1972) Foreign Aid under Wraps: The Point Four Program: 124.

17 Entre 1950 e 1957, Estados em desenvolvimento na Ásia, África e Oriente Médio receberam \$800.000.000,00 dólares de investimentos privados americanos, sendo durante o mesmo período ele havia crescido de $\$$ I I.5 bilhões para 25.4 bilhões de dólares em outras regiões do mundo.

18 Contabilizavam I.500 técnicos em diferentes países periféricos em 1953. No mesmo ano, cerca de I.000 técnicos e profissionais de diferentes nacionalidades estavam terminando sua formação nos Estados Unidos. Ver PATERSON, T. ( 1 972) Foreign Aid under Wraps: The Point Four Program: 125.

9 PATERSON, T. ( 1 972) Foreign Aid under Wraps: The Point Four Program: 125

20 A participação soviética nas políticas de desenvolvimento do Terceiro Mundo foi particularmente significante entre os países não-alinhados. A partir de 1955 e nos anos subseqüentes, Egito, Índia e Indonésia, por exmeplo, foram especialmente agraciados com ajuda externa soviética.
} 
dessa nova dinâmica competitiva era o reforço do terceiro mundo ${ }^{21}$ como campo por excelência do conflito bipolar global. Diante da veloz recuperação econômica dos Estados da Europa ocidental e, convencidos do potencial da ajuda externa para promover o crescimento econômico de Estados aliados, a administração Eisenhower criou a International Cooperation Administration (ICA), em 1955, com a finalidade de prover empréstimos direcionados a programas de desenvolvimento nos países "emergentes" e, ao mesmo tempo, contribuir para impulsionar a produção agrícola americana através da ampliação do mercado importador de suas mercadorias. Este programa foi usado sistematicamente, em particular, na relação construída com países "neutralistas" do terceiro mundo, entendidos dentro da perspectiva de potenciais futuros aliados. Sempre mantendo no discurso a defesa de uma ação com finalidade dupla, o presidente Eisenhower argumentava ser o investimento estrangeiro o motor do progresso econômico, além da arma mais eficaz para conter o avanço da influência marxista. ${ }^{22}$

A competição global pela hegemonia sobre o terceiro mundo, portanto, cresceu ao longo de toda a década de 1950 e 1960, sendo a "cooperação ao desenvolvimento" um dos principais instrumentos para se "comprar" aliados no formato Estado-cliente. Feita essa breve contextualização histórica, propomos em seguida analisar comparativamente os preceitos admitidos na elaboração dos programas de "ajuda ao desenvolvimento" entre Estados Unidos e União Soviética, começando pelo primeiro.

\section{A "PROMOÇÃO AO DESENVOLVIMENTO"ALÉM-FRONTEI- RAS NA POLÍTICA EXTERNA ESTADUNIDENSE}

Para se compreender as ações de política externa, importa também reconstruir o seu modo de interpretar o mundo para nele atuar. No caso da política externa estadunidense para o terceiro mundo, esta foi profundamente

\footnotetext{
21 O termo "Terceiro Mundo" foi criado pelo jornalista Alfred Sauvy em 1952 em artigo publicado no "L'Observateur" intitulado "Tiers Monde, une planete". "Tiers monde", nesse caso, faz referência aos países fora dos "mundos" comunista e "ocidental capitalista". O termo é ainda uma transposição do conceito de "terceiro estado" próprio da estratificação social francesa do período pré-revolucionário de 1789. Tratava-se da base da sociedade que, à época, buscava se organizar politicamente para ter atendidas suas demandas de classe. No caso do "Terceiro mundo", o termo foi popularizado após 1952 e obteve significações diferentes. Aqui, usamos como referência geográfica e política, sinônimo de "Estados emergentes", "países da periferia global" ou "países do Sul".

22 LATHAM, M (2000) Modernization as ideology: 27
} 
influenciada, durante o conflito da Guerra Fria, por uma visão de mundo determinada e uma teoria acadêmica normativa que embasava do ponto de vista teórico as estratégias adotadas. É importante, neste aspecto, destacar o papel da produção acadêmica estadunidense na elaboração de ferramentas teóricas e conceituais que servissem aos objetivos de política externa para a Guerra Fria. Essa espécie de fusão entre determinada produção acadêmica e as estratégias empregadas na política internacional já foi analisada por diferentes autores, sendo conhecida a penetração de acadêmicos em cargos estratégicos nas instituições do Estado americano, assim como a capacidade daqueles em influenciar na formulação de estratégicas políticas internas e externas. O historiador Stuart Leslie, por exemplo, chega a cunhar o termo "Military-Industrial-Academic Complex" para referir-se à influência particular que universidades como a Stanford University e a Massachusetts Institute of Technology (MIT) exerciam sobre o processo de tomada de decisão de certas instâncias oficiais. ${ }^{23}$

No caso americano, tanto a visão do "desenvolvimento" como as políticas que intervieram na promoção do processo de transformação do aparelho estatal e das estruturas sociais na periferia global são particularmente associadas à teoria da "modernização", originária da Universidade de Harvard mas rapidamente difundida nos diferentes meios acadêmicos nacionais. Será a interação entre pesquisadores originários das universidades e Think Tanks, que por vezes ocupavam as duas funções, que consagrará a esta teoria o papel de referência orientadora para a formulação de políticas voltadas para a promoção ao desenvolvimento na periferia global. A origem da teoria da "modernização" remonta ao trabalho de Talcott Parsons "The Structure of Social Action" de 1937, quando o autor se dedicava a analisar o papel do indivíduo no meio social. Para construir sua concepção de sociedade, Parsons se inspirava no liberalismo do século XIX e ressaltava o equilíbrio entre o poder de ação do indivíduo e os constrangimentos sofridos pelo meio social. Mais especificamente, as ações dos indivíduos seriam reguladas através das instituições que transmitem a ordem social e o equilíbrio. Os valores culturais, por sua vez, teriam poder para moldar uma ordem social integrada e estável. O "sistema funcionalista" de inter-

\footnotetext{
${ }^{23}$ Em seu livro, Leslie busca demonstrar como a Guerra Fria redefiniu a produção científica americana em diferentes áreas ao direcionar parte da pesquisa para interesses militares. Ver LESLIE, S. (1993) The Cold War and American Science: The Military-Industrial-Academic Complex at MIT and Stanford.
} 
pretação social, apresentado por Parsons em parceria com Edward Shils, tem como ideia central a correlação entre a atuação do indivíduo através seus diferentes papéis e personalidades desenvolvidas no meio social e as diferentes estruturas sociais. Os sistemas sociais encontrariam um equilíbrio consensual quando as necessidades do indivíduo fossem preenchidas pela estrutura social e pelos ideais culturalmente definidos.

Atento aos efeitos dos aspectos culturais sobre os indivíduos, Parsons apresenta uma explicação binária para a dinâmica evolutiva das sociedades através da dicotomia entre as condições "tradicionais" e "modernas". Por meio deste enquadramento, relações sociais complexas poderiam ser classificadas a partir de uma perspectiva progressiva. Dito de outra maneira, cultura, personalidade e sociedade seriam avaliadas com base na sua ênfase universalista ou particularista, coletivista ou individualista, especificista ou difusionista, sendo cada uma dessas características vinculadas ao "moderno" ou ao "tradicional". Sua sugestão era que certas forças estruturais tais como o aumento populacional, a divisão do trabalho e o avanço tecnológico servem para impor novas demandas à ordem social e, como conseqüência, exigem a transformação das estruturas sociais necessárias para manter estável o equilíbrio. Neste sistema, a natureza dos valores sociais é um elemento de profundo impacto na direção que a mudança social poderia tomar.

$\mathrm{O}$ "estruturo-funcionalismo", que corresponde ao método desta teoria, provém da busca por correlacionar as estruturas da sociedade com a performance de suas funções necessárias. Através deste arcabouço, estava estabelecido um modelo que pretendia observar as sociedades como sistemas integrados entre o político, o social e o econômico. Além disso, buscava firmar um método comparativo entre diferentes sistemas sociais a partir das necessidades básicas e das estruturas sociais, utilizando para tanto uma abordagem essencialmente a-histórica (ou de uma amplitude histórica reduzida e extremamente seletiva) e fundada sobretudo em estudos empíricos. Finalmente, após Parsons, diferentes seguidores como Lucien Pye e Daniel Lerner já apresentavam com maior nitidez o aporte evolucionista dentro de uma perspectiva histórica ao tratar de verificar empiricamente, através de estudos comparativos, a aplicação da teoria desenvolvida por Parsons. ${ }^{24}$ Desta

${ }^{24}$ A teoria social de Talcott Parsons deu origem a uma série de trabalhos específicos sobre o desenvolvimento em sociedades não ocidentais que engajavam tanto sociológos como economistas e cientistas políticos. Alguns exemplos são os trabalhos The family revolution in modern China (1949), de Marion Levy; The passing of traditional society, 
corrente, será Walt Rostow quem produzirá, já no âmbito da Guerra Fria, o trabalho de maior impacto sobre o uso da política externa para difundir os valores e o modelo de sociedade americano através do conceito-chave do "desenvolvimento".

Rostow, em seu principal livro "As etapas do desenvolvimento econômico" (1960), apresenta como questão central a maneira pela qual os Estados Unidos podem agir para orientar os homens políticos e os povos não comunistas das regiões periféricas para o "take off", isto é, o momento crítico do desenvolvimento onde a economia nacional superaria as resistências representadas pelas estruturas tradicionais no seio de sua sociedade e as substituiria por condições apropriadas ao crescimento econômico acelerado. Essa relação deveria permitir um crescimento durável, dentro de uma clima político e social adequado, deixando abertas todas as possibilidades para um desenvolvimento progressivo e democrático.

Como resposta, elabora um modelo etapista e evolucionista da história das sociedades humanas, a partir de uma história econômica eurocêntrica que objetiva elucidar dois pontos chave: de um lado, mostrar como os países então recentemente descolonizados poderiam estimular o crescimento econômico (e, por conseqüência, o "desenvolvimento") e, de outro, explicar porque o comunismo não poderia servir de alternativa para alcançar tais objetivos.

As cinco fases estipuladas pelo modelo rostowniano, a considerar o nível de desenvolvimento de cada sociedade, são as seguintes: a sociedade tradicional, as condições prévias para o "take off", o "take off", o progresso em direção à maturidade, a era do consumo de massa. ${ }^{25}$ Como se verifica, $\mathrm{o}$ modelo é bastante generalizador, pois pretende abarcar através de seu sistema de classificação evolucionista todas as sociedades existentes. Diante do contexto histórico no qual foi apresentado, direcionava-se diretamente aos Estados pós-coloniais da África e Ásia. O essencial, para o autor, consistia em passar da sociedade tradicional para a sociedade moderna. Para que isso pudesse ocorrer, era preciso viabilizar a etapa do "take off", conceito-chave de sua teoria. Sobre esta etapa, diz Rostow:

de Daniel Lerner; Becoming modern: individual change in Six developing countries, de Alex Inkeles \& David Smith. Michael Latham observa que Walt Rostow e seus colegas possuíam parcerias com policymakers do Departamento de Estado. $\bigcirc$ autor Latham faz um apanhado sobre as obras de referência dessa corrente. Ver : LATHAM, M(2000) Modernization as ideology: 55.

25 ROSTOW, W. (|96|) As etapas do desenvolvimento econômico. 
Atingimos agora um grande manancial da vida das sociedades modernas: a terceira etapa desta seqüência, o arranco ("take off'). É ele o intervalo em que antigas obstruções e resistências ao desenvolvimento regular são afinal superadas. As forças que contribuem para o progresso econômico, e que já haviam dado lugar a surtos e ilhotas de atividade moderna, dilatam-se e conseguem dominar a sociedade. $\mathrm{O}$ desenvolvimento passa a ser sua situação normal. Os juros compostos como que se integram em seus hábitos e em sua estrutura institucional. ${ }^{26}$

Michael Latham, em duas obras, expõe a relação orgânica entre a produção acadêmica de certo número de intelectuais (que em muitos casos também trabalharam em postos do Estado) e o direcionamento da política externa estadunidense no que diz respeito à promoção ao desenvolvimento. ${ }^{27}$ Conceitos que incorporavam a idéia de desenvolvimento e o expandiam, isto é, alargavam o caráter da transformação também para as instituições e os regimes, tais como "modernização" e "nation building", foram criados nas academias americanas e, de maneira gradual, incorporados ao jargão diplomático e à própria forma de compreender a Guerra Fria para nela agir. Difundidos através de congressos, revistas acadêmicas, mas também instituições internacionais cuja orientação era fundada sobre seus preceitos teóricos, "modernização" e "desenvolvimento" passaram a justificar e legitimar certas formas de intervenção internacional. A produção acadêmica assumia explicitamente, ao expor os objetivos de sua pesquisa, seu caráter utilitário à política do Estado. Como argumenta o autor, "modernização" seria sobretudo um meio para se compreender o processo de transformação global e identificar os meios pelos quais os Estados Unidos poderiam acelerar, modelar e dirigir tal processo. ${ }^{28}$ Essa interpretação expunha o papel central que uma teoria social possuía na elaboração da estratégia de projeção de poder do Estado americano. ${ }^{29}$

A teoria da modernização possui, grosso modo, quatro conceitos-chave. São eles: 1) sociedades "tradicionais" e "modernas" são separadas por

\footnotetext{
26 Idem: 20.

27 Os dois principais livros de Michael Latham que tratam do assunto intitulam-se "Modernization as ideology" e "The right kind of revolution".

28 Desde a Primeira Grande Guerra, as idéias sobre o desenvolvimento e a modernização eram já discutidas, e faziam referência a mudanças sociais, políticas e culturais. A variação americana dessa corrente se tornou profundamente ligada a política externa e moldada por convicções liberais e internacionalistas.

29 LATHAM, M (2000) Modernization as ideology: 2-5
} 
uma dicotomia; 2) as transformações políticas, econômicas e sociais são integradas e interdependentes; 3) o desenvolvimento leva ao Estado moderno através uma via linear e comum; 4) o progresso das sociedades em desenvolvimento pode ser acelerado através da ajuda e do contato com as sociedades já desenvolvidas.

Seus teóricos e defensores vislumbravam as sociedades ocidentais, industriais, capitalistas e democráticas como o topo desta escalada evolutiva histórica. Neste caso, os Estados Unidos seriam seu modelo histórico maior e, por conseqüência, aquele único legítimo a dispor de meios para impulsionar as sociedades "estagnadas" rumo a um assertivo processo transitório.

Segundo essa corrente teórico-normativa que balizava a formulação da política externa, o maior desafio do pós-Segunda Guerra era encontrar meios de projetar no mundo os valores sociais e liberais norte-americanos. Para que o objetivo fosse alcançado, era necessária a criação de organizações econômicas e estruturas políticas democráticas. A vitória, segundo apregoavam, dependeria tanto da aceleração do processo de transformação das sociedades "tradicionais" rumo ao "mundo moderno" como da capacidade de defesa face a ameaça comunista. ${ }^{30}$ Durante as décadas de 1950 e 1960 , a teoria da modernização serviu como orientação ideológica da política externa americana e forneceu a base teórica para sua auto-proclamada missão "modernizadora" do mundo.

Embora o cerne do conteúdo teórico já pudesse ser verificado na política americana desde o Point IV de Harry Truman, o modelo tal como exposto pela corrente modernista foi ter seu momento de maior predominância na orientação da política externa do Estado durante o governo de John Kennedy e Lyndon Johnson. Ali, a teoria estava formalmente consolidada na intelligentsia do Estado e intelectuais como Walt Rostow trabalhavam com grande influência junto aos círculos de poder. ${ }^{31}$ Assim, o conceito de "desenvolvimento" rostowniano e o papel estadunidense para sua promoção na periferia se configurada como uma dimensão relevante para a elaboração da política externa estadunidense, juntando-se a fatores outros como a necessidade de obter acesso aos recursos naturais, a busca pela manutenção de mercados abertos e a defesa de seus aliados europeus. Sua aplicação,

\footnotetext{
30 Idem: 6.

31 Walt Rostow, durante os governos John Kennedy e Lyndon Johnson, assumiu o cargo de Assistente Especial para Assuntos de Segurança Nacional.
} 
através das políticas de "cooperação ao desenvolvimento", estava circunscrita à dinâmica do jogo da Guerra Fria, estando os Estados receptores da "ajuda" estadunidense hierarquizados em termos de importância a partir de sua significância geopolítica e geoeconômica dentro do tabuleiro global.

A importância da estratégia de promover o desenvolvimento e a "modernização" cresce conforme acirra-se o conflito bipolar e a União Soviética engaja-se também na exportação de seu próprio modelo de desenvolvimento, após 1953. Como já dito, os Estados Unidos de Truman e Eisenhower, durante as décadas de 1940 e 1950, já haviam criado meios para usar seus recursos econômicos e sua expertise técnica para promover programas de transformação social e econômica tanto na Europa como nas "regiões emergentes". Tais iniciativas foram subseqüentemente seguidas e ampliadas pela administração Kennedy e Lyndon Johnson como resposta efetiva à propagação do comunismo no mundo pós-colonial. Como observou Latham, o que tornou a teoria da modernização tão interessante aos estrategistas dos Estados Unidos foi estabelecer a relação entre o desenvolvimento da periferia e os objetivos de segurança americanos. ${ }^{32}$

\section{A "PROMOÇÃO AO DESENVOLVIMENTO" ALÉM-FRON- TEIRAS NA POLÍTICA EXTERNA SOVIÉTICA}

Como mostrado acima, no contexto do pós-guerra, os países do Ocidente definiram uma política para os países em desenvolvimento bastante simples: transpor as revoluções industriais e o desenvolvimento econômico do Ocidente dos séculos XIX e XX para a periferia em poucos anos através de um processo de "modernização acelerada". O caminho se daria através de medidas assertivas de industrialização seletiva que proporcionariam o "take off” e encaminhariam o país à modernidade democrático-liberal.

A resposta soviética para as questões sócio-políticas colocadas pela descolonização, tais como a evolução das estratégias nacionalistas nativas e a ofensiva estadunidense na esfera do desenvolvimento, ocorreu de maneira mais discreta. Durante o período Stálin e, em particular, a partir do Sexto Congresso do Comintern de $1928^{33}$, foi definida a doutrina de

32 LATHAM, M. (20 I 0) The right kind of revolution: 3

${ }^{33}$ As primeiras formulações feitas de maneira sistemática na União Soviética sobre as linhas teóricas que estabeleceriam as diretrizes para eventos de sublevação nacional nas colônias e nos países menos desenvolvidos aconteceu durante 
política externa que orientaria o Estado soviético até morte de Stalin, em 1953 (exceção feita aos anos de aliança com o Ocidente durante a Segunda Grande Guerra). Tratava-se de uma visão dicotômica sobre a existência de "dois campos" dentro do sistema internacional, o comunista progressista e o capitalista imperialista. Tal perspectiva repercutiu no modo depreciativo como a União Soviética se interessou pelos movimentos de luta pela independência nacional, em função destes possuírem sua origem normalmente associada à reivindicações da classe burguesa.

Cabe aqui lembrar que este acirramento da posição soviética se deu a partir do ano de 1928. Até então, desde a revolução russa de 1917, persistia a idéia entre os estrategistas soviéticos da necessidade de se preservar uma aliança circunstancial nos países emergentes tanto com os partidos nacionalistas comandados pela burguesia nativa, dado seu caráter anti-imperialista, como com os movimentos proletários locais. A partir da nova perspectiva predominante entre os estrategistas soviéticos adotada em 1928, a emergência ao poder das elites nacionalistas no Terceiro Mundo passou a ser vista de modo majoritariamente negativo, sendo não raramente descritos como golpes orquestrados pelo Ocidente através de seus aliados dentro das burguesias nacionais. A preponderância da participação da classe burguesa nas manifestações independentistas passou efetivamente a ser visto como o fator crucial para o desconforto soviético com as novas lideranças. Tal interpretação serviu para afastar a política externa soviética das questões ligadas à descolonização. Na ocasião, admitia-se que o mundo colonial era

\footnotetext{
o segundo Congresso do Partido Comunista (1920). A maior questão discutida pela Comissão sobre a Questão Nacional e Colonial foi a relação entre os movimento de libertação nacional e os movimentos comunistas. As discussões giravam em torno da escolha sobre quem os partidos comunistas deveriam direcionar seu apoio, se aos movimentos de camponeses e trabalhadores ou aos movimentos nacionalistas. Ao fim, decidiu-se pelos dois, isto é, ao apoio à burguesia nacionalista independentista mas, também, ao comprometimento com toda forma de movimento operário. O quarto Congresso do Comintern, em 1922, também propôs uma aliança temporária com os movimentos nacionalistas liderados pelas burguesias locais. A Comissão sobre a Questão Nacional e Colonial também discutiu a questão das possíveis formas de desenvolvimento econômico dos futuros países. Na ocasião, o primeiro "teste" dessa política externa foi a revolução chinesa de 1925-1927, quando a União Soviética já estava sob o governo de Stalin. Embora já houvesse neste período algumas discussões no congresso sobre a possibilidade de uma via não-capitalista ao socialismo, e sobre o desenvolvimento não-capitalista de maneira geral, a nova política externa de Stalin a partir do sexto Congresso do Comintern (1928) definia a divisão do mundo em "dois campos" e era inflexível quanto à posições neutras. Dito de maneira breve, tal postura resultava da análise sobre as políticas de descolonização e em um contexto de concomitante internacionalização do capital, já que este buscava abrir as economias para as relações capitalistas de produção nos países emergentes e, assim, impossibilitava a capacidade desses movimentos de se engajarem num programa de transformação estrutural das relações de produção locais. Stalin terminou por acusar os golpes de Estado promovidos por movimentos nacionalistas de cooperação e submissão ao imperialismo. Ver HOSSEINZADETH, E. (1 989) Soviet non-capitalist development: 28-35.
} 
ainda uma zona de influência dos países ocidentais, assim como a América Latina, embora subsistissem em toda parte e ao longo de todo o período frágeis conexões entre União Soviética e movimentos e partidos comunistas locais (muitos dos quais na clandestinidade). ${ }^{34}$

A nova Ordem Mundial do pós-Segunda Grande Guerra e a morte de Stalin em 1953, somada à força do movimento terceiro-mundista pela descolonização e as novas estratégias de projeção da influência americana pressionaram a União Soviética para também reorientar sua forma de atuar no exterior. Uma corrente intelectual interna que já criticava a dicotomia "campo comunista" versus "campo imperialista" passou a projetar-se dentro dos círculos de decisão a partir da ascensão de Nikita Khrushchev ao poder soviético, apresentando uma resposta à veloz transformação da questão colonial em vias de se produzir. Desse modo, já no ano de 1953, a União Soviética decide se juntar à ONU na aplicação do Programa de Expansão da Assistência Técnica. Três anos depois, o vigésimo Congresso do Partido Comunista Soviético de 1956 proclamou errática a antiga análise dos "dois campos" ao mesmo tempo em que defendeu a necessidade de superar as teses do Sexto Congresso do Comintern de 1928 relacionadas aos movimentos de libertação nacional, dado seu teor "sectarista".

Desde então, um processo de revisão das abordagens prévias que diziam respeito aos movimentos de libertação nacional foi feito para que a criação de uma nova política para os países do Terceiro Mundo fosse elaborada do ponto de vista teórico. É preciso chamar atenção aqui para a pressão por substituir a doutrina anterior, dado que o acirramento da Guerra Fria impelia a União Soviética a valorizar a proximidade com uma periferia global por diferentes razões geoestratégicas. A nova orientação buscaria oferecer, para além de um programa de "cooperação para o desenvolvimento" (em diferentes âmbitos) com as novas Nações, um sistema teórico explicativo e compreensivo que validasse sua proposição como o melhor dentre os modelos de desenvolvimento disponíveis.

Mas como se daria essa via "alternativa" de desenvolvimento e porquê acreditar que ela poderia ocorrer? Segundo seus defensores, sua atração estava no potencial de permitir aos países agrários e pobres um meio eficaz para: 1) A eliminação do "atraso" a partir da transformação das relações de

34 Ver RESHETAR, J. ( 1 965) The Soviet Union and the Neutralist World: I03- 104. 
produção ultrapassadas para uma sociedade moderna e industrial; 2) Como conseqüência, o desenvolvimento gradual, consistente e pacífico rumo ao socialismo. A União Soviética, de sua parte, estaria pronta a dar o suporte na questão econômica e securitária, o que envolveria financiamentos e acordos comerciais vantajosos, armas, além do fornecimento de uma expertise técnica para viabilizar os projetos de industrialização e transformação da estrutura produtiva. Como observou Carlisle, os soviéticos acreditavam representar eles mesmos um caso bem sucedido de industrialização acelerada da estrutura produtiva, fator este que confirmaria a efetividade do seu modelo de desenvolvimento. ${ }^{35}$

Portanto, ao contrário da doutrina dos "dois campos" de Stalin, a nova teoria que embasaria a compreensão do conflito da Guerra Fria pelos soviéticos não somente passava a tolerar os movimentos de libertação nacional como também tratava-os como parceiros, dado que eram futuros potenciais aliados. Ao longo dos anos nos quais este programa será aplicado, os Estados não-alinhados serão o alvo prioritário. Assim, aqueles que posteriormente experimentaram a "via de desenvolvimento não-capitalista" seriam o Egito, a Síria, o Iraque, a Argélia, a Guiné, o Congo, a Somália, Burma, além de outros.

Embora a atuação externa para promover o "desenvolvimento nãocapitalista" nos países emergentes já fosse praticada desde 1954-1955, ${ }^{36}$ a apresentação formal desta teoria foi feita apenas na Conferência dos Partidos Comunistas e dos Trabalhadores, ocorrida em Moscou em 1960. ${ }^{37} \mathrm{Na}$ ocasião, cinco anos após Bandung, ela respondia à emergência dos países não-alinhados, entendidos como atores consolidados no sistema internacional, e explicitava uma política especialmente concebida pela União Soviética para estas Nações "neutralistas". Ao mesmo tempo formalizava, como contraponto à escola "modernista" estadunidense e sua considerável influência no mesmo período, o modelo soviético para o desenvolvimento, base teórica por onde o bloco soviético se nortearia ao direcionar seus recursos para a cooperação com o crescente número de países não-alinhados.

CARLISLE, D. (1964) The changing of Soviet Perception in the development process in the Afro-Asia World: 389.

${ }^{36}$ Os primeiros acordos de cooperação ocorreram com Egito e Afeganistão, tinham caráter de ajuda militar e respondiam a tentativa de enfraquecer o Pacto de Bagdá através de uma maior presença no Oriente Médio. Ver RESHETAR, J. (1965) The soviet Union and the Neutralist World.

37 HOSSEINZADEH, E. (1989) Soviet non-capitalist development: 40. 
A principal diferença com relação a política externa stalinista estava na forma como eram percebidos os estratos sociais que costumavam compor os movimentos independentistas. Enquanto Stálin definia a pequena burguesia, os partidos democráticos e os líderes nacionalistas como parte do "campo imperialista", a teoria do "desenvolvimento não-capitalista" os via como "democratas nacionais" que se radicalizavam devido as circunstâncias e lutavam contra o imperialismo e a burguesia compradore, construindo assim um ambiente favorável a sua transformação em uma sociedade socialista. ${ }^{38}$ Nessa nova visão, tanto a luta de classes como o papel das "forças proletárias" na transição para o socialismo adquiriam um papel secundário. A própria idéia de revolução era substituída por aquela de uma transição pacífica e gradual liderada pelas elites nacionalistas progressistas e respaldada pelas classes operárias. A mudança na interpretação, portanto, é gigantesca: as elites burguesas nacionalistas deixavam de serem vistas como eventuais aliados temporários do proletariado e do campesinato na luta anti-imperialista e passavam à condição de principal vetor da transformação da sociedade rumo a um Estado socialista.

Para justificar tais mudanças, os teóricos e estrategistas dessa corrente tratavam de sublinhar as novas condições históricas que caracterizavam aquele período. Entre elas estava a influência do campo socialista e o suporte que ele poderia oferecer a estes novos países. A força da via de desenvolvimento proposta pelos soviéticos estaria no exemplo de sucesso do modelo industrial da própria União Soviética e na disposição desta em prover os meios para que países emergentes pudessem repeti-lo em seus Estados. Com isso, apostava na comparação entre dois tipos de industrialização (socialista e capitalista) para sustentar a atração voluntária de lideranças do Terceiro Mundo ao campo soviético. Foi nessa linha que Papov, um dos principais teóricos do "desenvolvimento não capitalista", argumentou:

...under the influence of the theory and practice of world socialism, many petty bourgeois theories and policies in developing countries are undergoing significant changes. Revolucionary democracy emerged in consequence. ${ }^{39}$

${ }^{38}$ Idem, Ibidem.

39 PAPOV, Y. apud HOSSEINZADEH, E. (I989) Soviet non-capitalist development: 4I. 
Outra condição particular citada pelos teóricos face à nova conjuntura que se apresentava era a existência de múltiplos modos de produção e a peculiar e disfuncional estrutura social na maioria dos países em desenvolvimento, produto do sistema capitalista colonial que introduzira o modo de produção capitalista dependente ao mesmo tempo em que eram mantidas formas de organização social e cultural não-capitalistas. Alegava-se que a penetração do capital internacional nesses países criou uma burguesia reduzida no topo, uma pequena classe trabalhadora na base e um estrato maior e não facilmente classificável no meio, formado principalmente por pequenos empresários, artesãos, militares, intelectuais e outros. Estes não estariam satisfeitos com o status quo nem tampouco com as condições de mobilidade existentes. Seu papel é central na teoria pois seria este o estrato que constituiria potencialmente a frente nacionalista de combate ao imperialismo e o capitalismo. Isso porque representava não somente os interesses dos pequenos proprietários como também as aspirações dos trabalhadores, dos camponeses, dos intelectuais revolucionários e dos oficiais militares em seus países. Havia uma coincidência de interesses dentro do estrato social mais representativo que, no caso particular dos países pós-coloniais, secundarizaria a luta de classes para representar ele próprio o interesse nacional pela independência e o socialismo. Um dos principais textos de referência da teoria do desenvolvimento não capitalista, o livro "The role of the state in socio-economic reforms in developing countries" foi escrito por um grupo de quinze especialistas. Ali encontramos a seguinte interpretação sobre a estrutura das classes nos novos países do Terceiro Mundo:

For the most developing countries (especially in Africa and Asia), the rule of any one social class is made impossible by the historically shaped mix of different socio-economic structures (patriarchal, feudal, petty-commodity, etc...). A mixed socio-economic structure and the absence of clear-cut class differentiation has led to a situation in which, at the initial stage of the national liberation revolution, a bloc of various intermediate and middle strata...has come to power; as a rule, these strata represent more than half of the urban population. Their dominant and in a certain sense independent position in exercising state power stems from the fact that economic and political consolidation of classes is far from complete, while 
the bourgeoisie does not have sufficient power or experience in political organization to pretend to independent leadership. The level of socio-economic development in many thirdworld countries, particular in Africa, is such that we should speak not so much of the class nature of the state. While the intermediate that are in power retain the capacity to maneuver among specific classes and social groups, they represent not only their own interests, but also the interests of other social classes that are in the process of transformation. ${ }^{40}$

Para este grupo de estrategistas, o ambiente histórico "único" em termos domésticos e no âmbito internacional não somente favorecia a ascensão da pequena burguesia sob um regime representativo como fornecia um caráter especial ao processo histórico dos novos países. A relação entre luta de classes e o poder do Estado estaria, neste novo caso, redefinido: longe de ser o instrumento de domínio de uma classe sobre as demais, o Estado ocuparia o papel de regulador dos conflitos entre classes. ${ }^{41} \mathrm{O}$ "novo" Estado pós-colonial, através um regime de "democracia nacional" e dirigido pela vanguarda nacionalista progressista (pois a classe proletária ali ainda era incipiente e frágil), ocuparia o lugar de gestor de um aparelho administrativo capaz de prevenir o acirramento da luta de classes a partir da "aliança de todas as forças progressistas" ali representadas. A ameaça do imperialismo, através de suas investidas e sua aliança com golpistas internos, seria também dificultada a partir dessa aliança, o que ao final permitiria pôr em marcha o programa de "transição não capitalista" ao socialismo. Como definido pelos próprios teóricos:

The state of national democracy is a transitional form of administration. The mission of this state is to pave the way for transition from pre-capitalist relations to socialism, bypassing the state of capitalist development. Its political ground-work is the united national democratic front comprising all national democratic and progressive forces.

As the national democracy develops through revolution and evolution the state will gradually mould the society, crating the

${ }^{40}$ STANIS, V. et al. (1976) The role of the state in socio-economic reforms in developing countries: 34-35.

4I CARLISLE, D. (1964) The changing of Soviet Perception in the development process in the Afro-Asia World: 397-40 I. 
conditions for a step by step transition to a society in which socialist production relations will predominate. ${ }^{42}$

A transição ao socialismo se daria de modo particular. Através da planificação econômica e do exercício das atribuições organizativas da sociedade pelo Estado, os objetivos do programa de "desenvolvimento não-capitalista" seriam postos em prática e a sociedade, de maneira gradual e pacífica, se transformaria. Uma vez alcançado os objetivos, as organizações proletárias e camponesas, estimuladas por sua vez pelo Estado, atingiriam a maturidade e finalmente estariam aptas a assumir o controle da economia e a liderança da sociedade. Como bem observa Hosseinzadeh, na prática isso significava, segundo essa teoria, que uma vez completada a socialização das relações de produção pelo Estado "nacional democrático", isso teria por conseqüência o fim de seu próprio governo. ${ }^{43}$

O meio para se chegar ao socialismo deveria seguir os seguintes pressupostos: a) um relativo alto grau de desenvolvimento do setor estatal na economia; b) reformas agrárias (por vezes radicais) e o ativo encorajamento de cooperativas, especialmente no campo; c) modernização da agricultura e seu desenvolvimento; d) o uso de taxas, créditos e outras medidas financeiras para acelerar a industrialização e administrar outras prioridades econômicas; e) a introdução do sistema estatal de planificação do desenvolvimento econômico para contornar distorções na estrutura econômica inerentes do período colonial; f) utilização intensa de avanços tecnológicos e científicos; g) programas de treinamento de um corpo técnico administrativo capaz de resolver o problema do emprego e suprir a indústria com mão de obra qualificada; h) a atenção especial com a expansão das relações econômicas face a aceleração do crescimento econômico; e f) o incremento da independência econômica diante dos países imperialistas.

Com o objetivo de abrir-se aos "países emergentes" que voluntariamente escolhessem se incorporar, a orientação do bloco soviético estaria portanto redefinida a partir de dois eixos centrais: 1) da promoção dos partidos "nacionais democratas" no Terceiro Mundo, como já dito formados por membros de diferentes estratos da sociedade e que, embora tenham origem

42 STANIS, V. et al. (1976) The role of the state in socio-economic reforms in developing countries: 35.

43 HOSSEINZADEH, E. (1989) Soviet non-capitalist development: 42. 
não marxista, acabariam sendo direcionados ao socialismo científico; 2) da intensificação do comércio intra-bloco, a partir da institucionalização de organizações internacionais dedicadas a propiciar um ambiente favorável às trocas e à criação de uma união comercial. ${ }^{44}$

É interessante aqui ressaltar o horizonte de possibilidades aberto com a oferta de suporte e ajuda soviética aos países adeptos da via de "desenvolvimento não-capitalista". Ao aceitar o papel positivo das burguesias nacionalistas na direção do Estado dos países pós-coloniais, a União Soviética abriu na prática seu programa de "cooperação ao desenvolvimento" a quaisquer lideranças governamentais que desejassem estabelecer uma parceria, com nulas exigências sobre o modo autônomo destas gerenciarem a economia política interna, embora houvesse evidentes desgastes diplomáticos quando o governo "nacional democrático" usava a máquina do Estado para perseguir comunistas dentro de suas fronteiras. ${ }^{45}$ A possibilidade de se obter tecnologia, financiamentos e outros tipos de assistência econômica da União Soviética e de seus aliados terminou por prover, às lideranças nacionalistas emergentes, meios para que estas colocassem em prática suas estratégias de desenvolvimento nacional. Na perspectiva de diferentes lideranças do Terceiro Mundo, o fator importante neste cenário era a possibilidade oferecida pelos programas de ajuda soviética para que fosse reduzida a dependência das economias ocidentais e, conseqüentemente, a subordinação à determinadas exigências que estas normalmente impunham quando forneciam seu próprio programa de ajuda.

Como conseqüência da entrada da União Soviética na disputa pelo Terceiro Mundo, o próprio programa de "cooperação ao desenvolvimento" estadunidense respondeu com uma flexibilização ainda maior do que aquela determinada em sua origem nos governos Truman e Eisenhower, isto é, desassociando em certa medida a "ajuda" (embora não em todos os aspectos) da adoção de determinadas reformas econômicas internas e a certas exigências de ordem geopolítica como a participação em alianças militares.

44 Idem: 50

45 autor Carliste descreve, em particular, como o apoio soviético aos movimentos nacionalistas a determinados países da África e Ásia terminou por isolar os partidos comunistas nativos, quando estes existiam. Ver CARLISLE, D. (1964) The changing of Soviet Perception in the development process in the Afro-Asia World: 393-394. 


\section{AS TEORIAS SOBRE A COOPERAÇÃO PARA O DESENVOL- VIMENTO EM PERSPECTIVA COMPARADA}

Produzidas, portanto, dentro de um contexto de clivagem política e ideológica, a teoria da "modernização" e a teoria do "desenvolvimento não-capitalista" compunham ambas um emaranhado de proposições interpretativas com diversas funções: eram propagandistas, educativas, normativas, justificavam a adoção de uma certa política externa por parte de cada potência e eram respaldadas pelo "cientificismo" acadêmico.

Não interessa aqui apontar as contradições e incoerências existentes em cada uma das duas teorias no que concerne a "ajuda" externa ao Terceiro Mundo, mas sim evocar as semelhanças entre elas em cinco aspectos-chave: a) ambas entendiam a "cooperação ao desenvolvimento" como instrumento efetivo de política externa face ao conflito da Guerra Fria, sendo sua importância de primeira ordem para a arregimentação de novos aliados entre os "países emergentes"; b) O "desenvolvimento" como processo em si é, em ambos os casos, um conceito evolucionista e mecanicista, com referências comuns à industrialização (com especial atenção a formação de uma indústria de base), a reforma agrária e a presença decisiva do Estado como vetor do desenvolvimento. ${ }^{46}$ Com isso, tornava-se difícil classificar entre "modernistas" e "não-capitalistas" as diferentes experiências de transformação econômico-social dos países "neutros", caso fosse tomado em consideração apenas uma análise sobre a economia política; c) Essa coincidência sobre aspectos fundamentais no modo de "desenvolvimento" entre duas teorias que se pretendiam opostas resultava, ao final de sua aplicação, na quase nula associação da "cooperação ao desenvolvimento" à exigência de reformas econômicas internas, já que não era este um critério propriamente diferenciador que justificasse privilégios; d) Os modos de cooperação podiam ser divididos, fundamentalmente, em três tipos: militar (que fundamentalmente significava transferência de armas), econômico (financiamentos, empréstimos vantajosos e acordos comerciais bilaterais) e auxílio e formação técnica de uma elite qualificada para a administração da máquina estatal e para o gerenciamento da produção industrial; e) O que

A diferença maior estaria na ênfase dada ao papel da empresa privada e dos investimentos privados por parte dos "modernistas" e ao papel das cooperativas no campo dado pela teoria do "desenvolvimento não-capitalista".

Ainda assim, é uma diferença de ênfase, que não implica uma rejeição de um ao outro. 
viria a definir o grau de "ajuda" que cada uma das potências estaria disposta a fornecer era, essencialmente, o peso geopolítico disposto pelo país demandante dentro da dinâmica do conflito bipolar, assim como o risco potencial de "perdê-lo" à potência rival, dentro de circunstâncias conjunturais dadas. A "ajuda" ao desenvolvimento estava, portanto, inteiramente associada ao âmbito securitário e militar.

Mas a construção de sistemas explicativos por detrás da implementação de políticas de cooperação" não deve ser lido apenas como um suporte do meio "científico" para a consecução de uma estratégia de potência. $\mathrm{O}$ argumento que cada teoria continha buscava cativar os tomadores de decisão, a elite tecnocrática dos países subdesenvolvidos, e respondia aos anseios próprios dos movimentos nacionalistas emergentes. O objetivo era a construção de um Estado moderno, à imagem das instituições e do modo de produção existente nos países industrializados, que fosse capaz de produzir riqueza compartilhada, construir uma nação a partir da redução das clivagens sócio-econômicas internas e garantir a governabilidade e a segurança territorial. Em outras palavras, as teorias embasavam os termos por onde as negociações, os contratos e o jogo de barganha entre o Estado receptor e o Estado provedor se daria. Ao aceitar a ajuda externa, o Estado receptor se incorporava, de certa forma, as mesmas narrativas históricas, além dos mesmos pressupostos conceituais definidos pelo Estado provedor. Estados Unidos e União Soviética, dessa maneira, utilizavam os programas de cooperação para criar periferias sistêmicas a sua imagem e semelhança, homogeneizando seus clientes e garantindo com isso uma maior penetração de seus interesses geoestratégicos.

Atualmente, e após o fim da Guerra Fria, os programas de cooperação internacional para o desenvolvimento mudaram seus métodos, assim como a dinâmica que impulsiona os atores fornecedores não é mais aquela do conflito bipolar. O papel das agências transnacionais, em particular, cresceu enormemente, assim como a participação de países considerados em desenvolvimento. Entretanto, o aspecto político continua profundamente associado à implementação dos programas. As associações entre o presente e as circunstâncias históricas que impulsionaram os programas de ajuda no contexto da Guerra Fria são possíveis de ser feitas, e seria interessante, visando a confecção de futuros trabalhos, estabelecer parâmetros compa- 
rativos que permitam identificar as continuidades e as rupturas no atual contexto de elaboração e implementação das políticas de cooperação para o desenvolvimento.

\section{THE RIVALRY BETWEEN THE UNITED STATES AND THE SOVIET UNION AND THE PROMOTION OF DEVELOPMENT IN THE GLOBAL PERIPHERY}

\section{Abstract}

The current article aims to analyze instrumental aspects from the "Modernization theory" and the "Non-capitalist development theory" underlying development aid programs respectively from United States and Soviet Union during the Cold War. Both theories were elaborated as a response to the growing systemic rivalry between superpowers and in synchrony with their respective and distinct geopolitical objectives. However, it is argued that despite the rivalry between superpowers there were substantial similarities on how each theoretical framework proposes the necessary politics to promote economic development in peripheral countries.

Keywords: Modernization, Non-capitalist development, Cold war, International cooperation, Third World.

\section{JEL Classification: F51.}

\section{BIBLIOGRAFIA}

BASTOS,C. \& BRITO,G. Introdução. In AGARWALA, A.N. \& SINGH, S.P. (org.) A economia do subdesenvolvimento. Contraponto, Rio de Janeiro: 2010.

CARLISLE, D. The changing of Soviet perception in the development process in the Afro-Asian World. In: Midwest Journal of Political Science, Vol.VII, N. 4, November 1964: 385-407. 
CONTE, A. Bandoung, tournant de l'Histoire. Robert Laffont, Paris, 1965.

CURADO, P. A Guerra Fria e a cooperação ao desenvolvimento com os países não-alinhados: um estudo de caso sobre o Egito Nasserista (19551967). Tese de Doutorado. PEPI/IE/UFRJ, 2014.

HOSSEIN-ZADEH, I. Soviet non-capitalist development: the case of nasser's egypt. Praeger Publishers, 1989.

KENNEDY, P. Ascensão e queda das grandes potências, a transformação econômica e o conflito militar de 1500 a 2000. Editora Campus, Rio de Janeiro, 1989.

LATHAM, M. Modernization as ideology, American social science and "Nation Building »in the Kennedy Era. University of North California Press, 2000.

LESLIE, S. The Cold War and American Science: The Military-IndustrialAcademic Complex at MIT and Stanford. Columbia University Press, New York: 1993.

MONIZ-BANDEIRA, L. Formação do império americano. Civilização brasileira, Rio de Janeiro, 2005.

Point Four Speech. Em: http://www.bartleby.com/124/pres53.html. Acessado dia 10/10/2013

PATERSON, T. (1972) Foreign Aid under Wraps: The Point Four Program. In: The Wisconsin Magazine of History, Vol. 56, N. 2 (Winter, 1972-1973), pp. 119-136.

RESHETAR, J. The Soviet Union and the Neutralist World. In: American Academy of Political and Social Science, Philadelphia, 1965, p. 102-112. 
RIST, G. Le développement, histoire d'une croyance occidentale. Sciences Po Press, Paris, 2013.

ROS, J. (2005) The pioneers of developmente economics. In: JOMO, K.S. \& REINERT, E.S. The origins of development economics.

ROSTOW, W. As etapas do desenvolvimento économico: um manifesto não-comunista. Zahar Editores, Rio de Janeiro : 1961.

STANIS, V. et al. The role of the state in socio-economic reforms in developing countries. Progress Publishers, Moscou: 1976. 